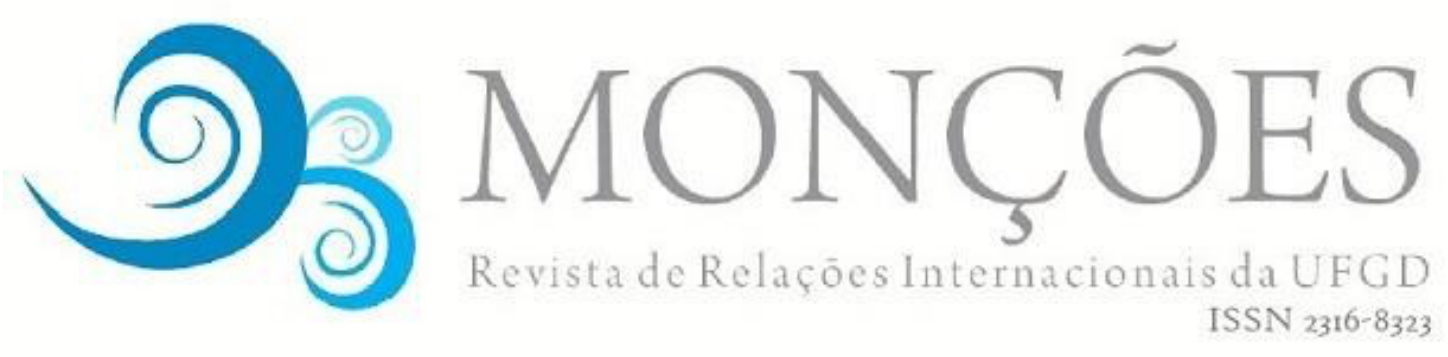

\title{
ENTREVISTA COM DUVAL MAGALHÃES FERNANDES
}

Entrevistadores

Marco Aurélio Machado de Oliveira

Professor do Mestrado em Estudos Fronteiriços da UFMS

Hermes Moreira Jr. Professor da Faculdade de Direito e Relações Internacionais da UFGD

Duval Magalhães Fernandes é Professor do Departamento de Economia e do Programa de Pós-Graduação em Geografia da Pontifícia Universidade Católica de Minas Gerais (PUC-MG). Graduado e Mestre em Economia pela Universidade Federal de Minas Gerais (UFMG) na década de 1970, especializou-se em Demografia na tradicional École des Hautes Études en Sciences Sociales, em Paris, área na qual se tornou Doutor, anos mais tarde, novamente na UFMG. Realizou Pós-Doutorado no Instituto Ortega y Gasset, em Madri, foi consultor do Ministério das Relações Exteriores do Brasil, do Programa das Nações Unidas para o Desenvolvimento (PNUD), do Alto Comissariado das Nações Unidas para Refugiados (ACNUR) e Professor Visitante na Universidad Cayetano Heredia, em Lima. É uma das principais referências brasileiras em estudos sobre migrações internacionais, tendo sido um dos pioneiros a pesquisar a migração haitiana em nosso país. É Bolsista Produtividade em Pesquisa do CNPq. 


\section{PERGUNTA. Como o Sr. avalia os fluxos migratórios na atualidade e seus impactos em nosso continente?}

RESPOSTA: Ora, os fluxos migratórios na atualidade têm grande impacto em nosso continente. Estados Unidos, Canadá e, em alguns casos, o México são países que atraem imigrantes. No caso do México, é um país de emigração e de imigração e, atualmente, também de trânsito. Na América do Sul, temos a situação venezuelana, que hoje chama mais a atenção por conta do volume de migrantes que têm saído do país, principalmente em direção à Colômbia, Peru, Equador, Chile, ficando o Brasil em quinto lugar, neste aspecto. Por outro lado, em momento mais recente neste decênio, a partir de 2011, o Brasil foi um local para onde se dirigiram vários imigrantes do Haiti. Em termos da América do Sul, o Brasil foi o primeiro país para esse fluxo migratório que, de certa forma, continua, mas não na mesma intensidade do passado, mas é um fluxo presente. Neste caso, o Brasil, para alguns haitianos, virou país de destino, dentro de seu projeto migratório, e para outros foi, simplesmente, um país de trânsito, no trajeto para os Estados Unidos, que é o projeto maior de parcela considerável de haitianos, mas, também, em direção ao Chile ou outros países da América do Sul. Hoje esse processo refluiu, e as dificuldades em termos de continente, com as políticas, principalmente do governo estadunidense, que de certa maneira influencia as políticas migratórias em outros países da região, torna esse trajeto em direção aos Estados Unidos, ou mesmo ao Canadá, de muita vulnerabilidade e de elevadíssimo risco.

\section{P. Ainda sobre o nosso Continente, as respostas governamentais a esses fluxos têm produzido que tipo de efeitos?}

R: Como mencionado, as respostas governamentais, atualmente, não são autônomas. Por exemplo, a medida do governo mexicano em cercear alguns movimentos pela fronteira sul em direção à fronteira norte, claramente em direção aos Estados Unidos, foi de certa forma delineada, desenhada, pelos estadunidenses que exigiram do país, via chantagem econômica, postura mais firme no sentido de impedir a entrada de imigrantes que queriam, simplesmente, transitar pelo México. Não podemos esquecer que, em passado não muito longínquo, os mexicanos, 
também por pressão do governo americano, passaram a exigir dos brasileiros visto de entrada no país. Podemos esperar, quem sabe, uma situação semelhante no futuro. Na América do Sul, o atendimento aos imigrantes venezuelanos, principalmente no Brasil, dentro do formato que vem sendo utilizado hoje, tem forte influência do governo americano por conta de seus interesses na região. Assim, de uma maneira geral, podemos dizer que os governos não têm sido autônomos na tomada de decisão em relação à migração internacional. Esses seguem algumas normas políticas de outros países. Por exemplo, dentre as diversas teorias que buscam explicar os motivos dos haitianos terem optado por vir ao Brasil, há aquelas que veem nessa migração um dedo dos Estados Unidos no sentido de dirigir esse fluxo que poderia fluir para aquele país por conta do terremoto de 2010 no Haiti. O que mostra tudo isso é que não temos políticas migratórias autônomas, mas sim propostas para atender a interesses políticos de países com importante influência econômica na região.

\section{P. O Conjunto de mecanismos internacionais é adequado para atender a realidade atual de fluxos migratórios?}

R: O Pacto Global para migração, celebrado em 2018 sob os auspícios da ONU, é, no momento, o mecanismo mais importante de governança migratória na comunidade internacional. No entanto, é interessante notar que países que tiveram forte fluxo de imigrantes em período recente, e que também são países governados por partidos populistas de direita, foram os que se recusaram a assinar o documento final do Pacto Global. Nesse grupo estão os Estados Unidos, a Hungria, a Polônia e, após alguma hesitação, o Brasil. Os Estados Unidos vinha participando do processo de construção do Pacto Global e quando o Partido Republicano chega ao poder o presidente faz saber que entende a migração como uma prerrogativa de políticas internas americana e que não tem nenhuma relação com o resto do mundo. As decisões, portanto, são internas, de governo, e atingem os migrantes, mas sem que tenha relação com outros governos no âmbito de um pacto multilateral. No caso do Brasil, essa saída, possivelmente, foi só uma demonstração de boa vontade para com o vizinho do norte, e mostrando que a política na área internacional seria a de um alinhamento direto e instantâneo com os Estados Unidos, ou com as decisões 
americanas. Certamente, em se tratando da migração, o Brasil não tem uma proposta de política regional. No caso da migração venezuelana na região, países com governos identificados como conservadores, ou mesmo populistas, formaram o que é conhecido como Grupo de Lima, e a partir daí pressionaram o governo venezuelano para tomar medidas contra a migração, mas, também, de forma concertada, fizeram intervenções diretas na política interna do país, com apoio explícito às tentativas de golpe de Estado ou mesmo de gerar incidentes nas fronteiras com Venezuela. Exemplo disso foi a tentativa de entrada forçada de comboios humanitários que partiram da Colômbia e a pífia tentativa de fazer o mesmo na fronteira entre Venezuela e Brasil. Em resumo, certamente não temos um mecanismo internacional adequado para governança migratória. Busca-se hoje, se formos olhar o caso da Europa, algum entendimento em termos de atendimento e recebimento de imigrantes, mas de qualquer maneira ainda não é algo que possa ser considerado como uma política regional estabelecida. Houve sim a tentativa do Pacto Global, mas que até o momento ainda não mostrou seus efeitos. Mas, conseguir chegar ao primeiro documento acordado entre os países, mesmo que não seja um texto impositivo, é um grande avanço considerando as situações que ocorreram no passado.

\section{P. Como o Sr. avalia a participação do Brasil nesse contexto?}

R: Lamentavelmente o Brasil tomou a posição de ir contra a tentativa de um acordo multilateral relativo à imigração, que foi o Pacto Global. É interessante que o país sempre participou de todos os fóruns no qual o tema foi debatido, foi um dos países que tomou a frente em termos de trabalhar a questão desse acordo global, mas na mudança de governo ele se retira. O que chama a atenção é a tentativa de reaplicar no Brasil algumas das medidas do governo estadunidense, que tem por tradição atuar no cenário internacional com a visão bilateral e não multilateral. Vimos, em 2019, a postura de rejeição dos ministros da Economia, das Relações Exteriores, e do próprio Presidente brasileiro em relação ao MERCOSUL, mesmo que ao final, quando apareceu o acordo com a União Europeia, tiveram que voltar atrás e enaltecer a importância desse acordo, mesmo mantendo tentativas de acordos bilaterais. A questão do acordo de livre trânsito no MERCOSUL funcionou no sentido 
de regularizar a situação de vários imigrantes de países da região, mas ainda está longe de ser um acordo que permita efetivamente um trânsito. Trânsito este que se estivesse em uma situação ideal, permitiria, não apenas as pessoas, mas, também, as pessoas com seus títulos acadêmicos, suas qualificações profissionais, trabalharem em um ou outro país, sem a necessidade de validação de diplomas ou certificados. Então, ainda temos muito o que caminhar para conseguir chegar ao ponto de ter um real livre trânsito de pessoas no âmbito do MERCOSUL. No plano internacional, o Brasil tem se mostrado muito aberto à questão do acolhimento de refugiados, principalmente de sírios, mas é claro que devemos lembrar que nós não estamos em uma fronteira com o país em conflito. Então, os sírios têm que fazer todo o trajeto desde o local de residência ou refúgio até o Brasil, e o fazem por conta própria, o que cria uma limitação em relação ao número de pessoas que conseguem chegar ao país, um pouco distinto do que acontece na Europa ou em países próximos às zonas de conflito. $\mathrm{O}$ que nós assistimos hoje no discursos de alguns setores, ao tratarem da legislação brasileira, é tentar modificar artigos da nova Lei de Migração (Lei 13.455 de 2017) incluindo alterações que buscam resgatar pontos da antiga Lei, o Estatuto do Estrangeiro (Lei 6.815 de 1980), que tinha como inspiração a preocupação com a Segurança Nacional e não os direitos dos imigrantes. Propostas de projetos no Senado Federal buscam desvirtuar o espírito da nova lei da migração, incluindo nela a possibilidade de perseguição ao estrangeiro, sua prisão e expulsão, por uma mera solicitação de um juiz. Nós já vimos em outros casos da história recente da política brasileira um juiz de primeira instância assumir poderes quase ditatoriais, tomando a si todas as questões relativas à condenação e julgamento de pessoas sem ter em conta os direitos constitucionais dos acusados. Fica a pergunta o que poderia acontecer com um estrangeiro?

P. Há sinergia entre organismos internacionais, organizações nãogovernamentais e o poder público no Brasil para evitar crises decorrentes desses fluxos?

R: É muito interessante quando comparamos dois fluxos migratórios recentes que tiveram o Brasil como destino: a migração de haitianos e a migração de venezuelanos. O primeiro iniciado ao final de 2010, com maior volume em 2014 e 
2015, e ainda presente, em menor escala em 2019. A migração venezuelana está em processo crescente cujo final não pode ainda ser previsto. Em termos de volume daqueles que permaneceram no Brasil, o resultado é quase similar, é lógico que pela proximidade da Venezuela, e pelo volume de sua população, os números são um pouco maiores. Por exemplo, houve, até meados de 2019, a entrada de venezuelanos de aproximadamente 400 mil, mas a permanência é de 140 mil a 150 mil pessoas. No caso dos haitianos podemos falar de um total de $100 \mathrm{mil}$ a $110 \mathrm{mil}$ pessoas. Isso indica que a magnitude das duas comunidades, dos dois fluxos, é bastante próxima. No caso dos haitianos, de forma distinta do que aconteceu com os venezuelanos, o país de origem não faz fronteira com o Brasil. Uma vez chegando ao destino e com poucos recursos não havia forma de retornar ao ponto de partida. Então, neste caso, só havia uma possibilidade: ir em frente. Sua migração agora era continuar aquele projeto, ou aquele processo. No caso venezuelano, ainda há possibilidade de retorno próximo à fronteira, mesmo assim, um conjunto de migrantes ficou no país. Em primeiro lugar é importante destacar que nos dois casos, na fase inicial, foi a sociedade civil, principalmente as organizações religiosas, que tomou a frente do processo de acolhida, estando junto aos migrantes, buscando atender às suas necessidades, e tentando de certa forma auxiliar na preparação de documentação para que pudessem apresentar as suas demandas ao governo brasileiro, isto é, uma demanda de visto temporário ou de refúgio, no caso dos venezuelanos, e no caso dos haitianos, a solicitação de refúgio. No caso dos haitianos essa presença foi muito forte, praticamente durante todo o processo, perdurando até hoje. No caso dos venezuelanos, essas organizações estiveram no momento inicial auxiliando não só os imigrantes, mas também os órgãos de governo que não tinham como responder ao fluxo dos imigrantes. Quando a situação tomou maior amplitude os organismos internacionais começaram a intervir e na medida que o processo avançava o governo federal passou a ter maior protagonismo montando o projeto "Operação Acolhida", coordenada pelas forças armadas. É nesses aspectos que as diferenças são enormes. Se no caso dos haitianos não víamos os uniformes das Nações Unidas, com os símbolos de cada uma das agências, não víamos a comunidade de organismos internacionais, ONGs internacionais, apoiando e trazendo recursos, no caso dos venezuelanos essa presença tornou-se clara. No âmbito da administração pública, no caso dos haitianos, era o governo estadual e o 
governo municipal que estavam à frente do processo, tanto nos pontos de entrada na fronteira como nas cidades de destino e, eventualmente, o governo federal com algum pequeno auxílio. No entanto, foi a sociedade civil que buscou caminhos para que esses imigrantes pudessem sair da fronteira norte, indo para São Paulo, ou para o sul do país, locais onde seria possível encontrar opções de trabalho. Até mesmo empresários tomavam a frente e iam buscar esses imigrantes na região norte. $\mathrm{O}$ contexto econômico no qual acontece a migração venezuelana é completamente distinto e as oportunidades de emprego não são tão grandes como no início da década de 2010. Nesse quadro, os organismos internacionais, o governo federal e os militares passam a coordenar o processo de gestão do recebimento dos imigrantes da Venezuela. Apesar de algumas vozes na área federal insistirem em colocar que o governo federal não teria condições de assumir todo esse processo, a realidade mostra que a sociedade, governo federal e organizações da sociedade civil têm em mãos os mecanismos, legais e materiais necessários para a gestão de fluxos migratórios. Mecanismos esses construídos com base nas lições aprendidas na gestão do processo migratório dos haitianos. No momento, o que assistimos, com apoio de organismos internacionais, é a militarização da governança migratória no país, o que pode indicar, para o futuro, a transformação da migração internacional em uma questão na qual a segurança nacional poderá ter prioridade em contraposição aos direitos dos imigrantes.

\section{P. Qual sua avaliação sobre o estado da arte das pesquisas sobre fluxos migratórios no Brasil e na América Latina? De que modo o conhecimento que vem sendo produzido tem subsidiado a formulação de políticas públicas?}

R: Na América Latina e Caribe e na América do Norte, principalmente no México, a produção acadêmica sempre foi muito rica. Certamente, a migração no México, mais especificamente para os Estados Unidos, é um processo muito antigo, assim como na América Central. São países que passaram por situações de crises internas que desaguaram em muita violência contra a população, o que leva, lógico, a um processo migratório inter-regional. No caso da América do Sul, a produção acadêmica é grande e tem uma tradição, principalmente na Argentina, no Chile, países com históricos de imigração, mas nos anos de 1970 e seguintes, por razões políticas e econômicas tiveram forte emigração. Há também países que, 
historicamente, têm processo de emigração como o caso da Bolívia e do Equador. No Brasil, é interessante que não se tem um registro muito grande da produção acadêmica. Se olharmos a base da CAPES, que tem os registros da produção de teses e dissertações elaboradas no país, até o ano 2000 , não se tinha um volume de produção na área de ciências humanas e sociais que tratasse a migração internacional que poderia ser considerada como uma grande produção. Foi necessário chegar a meados da primeira década deste século para que alcançássemos o volume de mil produções quer sejam de teses ou dissertações sobre migrações internacionais. Um marco interessante nessa discussão sobre a migração internacional foi, em 1995, quando a Professora Neide Lopes Patarra, à época na Unicamp, com um projeto apoiado pelo Fundo de Populações das Nações Unidas, fez um aprofundado levantamento sobre o tema, convidando vários especialistas para tratar a migração internacional. Esse projeto levou a duas publicações e se pode dizer que são publicações seminais com relação à migração internacional no país. É claro que outras publicações, outros importantes trabalhos existiam à época, mas esse foi um esforço de compilação do estado da arte sobre a migração internacional no país. Após a criação da Comissão Nacional de População e Desenvolvimento (CNPD), em 1995, a discussão do tema ganhou visibilidade com a elaboração de um estudo, coordenado pela Professora Mary Castro, sobre a migração internacional no Brasil. Esse trabalho foi também um marco em relação ao tema. Hoje, após a chegada dos imigrantes haitianos e também a chegada dos venezuelanos, há extensa produção na área das migrações internacionais. É importante ressaltar os trabalhos que tratam da migração de brasileiros em outros países. Os primeiros textos remontam aos anos 1993, 1994. São relevantes trabalhos que tratam da comunidade de brasileiros nos Estados Unidos, Portugal, Inglaterra e outros países. De qualquer forma, é nos anos 2000, e praticamente após os 2010, que efetivamente vamos poder dizer que temos uma situação da migração internacional sendo um objeto de estudo da nossa comunidade de pesquisadores. Hoje vários centros têm seus observatórios de migração, com destaque para o Observatório na Unicamp, possivelmente o que tem maior produção na área, e há trabalhos que envolvem até a produção de dados como o caso do observatório da UnB (OBMIGRA), que tem convênio com o governo federal e está disponibilizando os registros administrativos de várias fontes. Na realidade, o que podemos dizer é 
que no caso do Brasil, é no momento atual que dispomos de elementos para avançar mais nos estudos da migração internacional, e não depender única e exclusivamente do Censo demográfico que, infelizmente, em 2020 irá retirar uma das questões que seriam mais importantes para aqueles que analisam a saída de brasileiros para outros países. É lamentável que aqueles que deveriam estar trabalhando para melhorar a qualidade da informação, são insensíveis para o tema. Mesmo assim, creio que vai ser possível avançar nessas análises no futuro.

\section{P. Quais dificuldades o sr. enxerga na integração dessa população migrante à sociedade brasileira, sobretudo nesse nosso contexto atual?}

R: Não há como negar que o Brasil tem uma tradição histórica na recepção de imigrantes, mas, ao final da década de 2000 , a chegada de imigrantes de várias partes do mundo mostrou a outra face da moeda construída no mito da cordialidade. $\mathrm{Na}$ realidade, foi mostrada a face da xenofobia associada ao racismo, sempre presente, e também à intolerância, que tinham maior ou menor ênfase dependendo da situação. No caso dos haitianos e senegaleses que chegaram ao Brasil no momento da Copa do Mundo e das Olimpíadas, a questão racial falou mais forte. Em outro momento, na cidade de Belo Horizonte, um imigrante estadunidense foi agredido por razões homofóbicas. Então, no caso do Brasil, eu acredito que não temos no trato com o imigrante só a prevalência da xenofobia, temos sim o racismo e homofobia, e todas as outras situações de segregação que podemos colocar. A partir deste ponto vemos que a integração desses imigrantes na sociedade brasileira, principalmente aqueles em situação de maior vulnerabilidade, é sempre difícil. Ainda encontramos pessoas que dizem que os imigrantes estão tomando os postos de trabalho de brasileiros. No entanto, não se comenta sobre a situação daqueles imigrantes que contribuem para o crescimento do país, ou mesmo, de uma maneira mais simples, no aumento das oportunidades de emprego. Volto a mencionar a cidade de Belo Horizonte, onde, assim como em outras cidades, há vários pequenos restaurantes, alguns familiares, que trabalham com a culinária árabe. São restaurantes que pertencem a imigrantes recentes, em sua maioria refugiados que vieram da Síria, e em cada restaurante, apesar da estrutura familiar, é possível encontrar um, dois, até três auxiliares que são brasileiros. Isto é, são 
brasileiros que estão tendo emprego por conta da chegada desses imigrantes. Ao contrário de tomar postos de trabalhos, eles estão abrindo portas para que brasileiros possam ter um emprego. Poderia citar outros exemplos como a comunidade chinesa que tem grande participação no comércio nos shoppings populares, nos quais a mesma dinâmica de criação de postos de trabalho acontece. A integração se faz, em primeiro lugar, pelo idioma, e não temos uma política pública que garanta a oferta de cursos de idioma português. O que temos são algumas atividades em uma ou outra escola, na maioria dos casos cursos oferecidos por organizações da sociedade civil, mas não uma política, como a do EJA, que possa oferecer o ensino do nosso idioma para os imigrantes como uma obrigação na esfera municipal, na cidade de residência do imigrante. Certamente tal política iria, em muito, contribuir para a integração do imigrante. Outro aspecto importante é trabalhar nas escolas, junto às crianças e jovens, a questão da migração, construindo ali a cidadania, no sentido de incorporar a ideia do imigrante, do outro, que está no país com direitos iguais a todos os cidadãos. Dentro do contexto atual, o que temos visto em termos de declarações do governo federal, ou de alguns representantes desse governo, ou de grupos que apoiam incondicionalmente o governo, são sinais claros de uma tentativa de implantar a xenofobia no país, como também incentivar a xenofobia contra brasileiros no exterior. Não pode ser esquecida a fala do Presidente da República, quando esteve nos Estados Unidos, e em um pronunciamento chamou de vagabundos os brasileiros que ali trabalhavam. O Presidente se esqueceu, ou não quis lembrar, de que parte do resultado positivo da balança de pagamentos do Brasil vem de recursos encaminhados pelos migrantes para o país, ou seja, as remessas. Na primeira década dos anos 2000 , em 2005, 2007 e 2008, esses recursos representavam mais que as nossas exportações de café, ou mesmo a exportação de veículos de passeio. Eram recursos que entravam no país com sinal positivo e contribuíram de maneira explícita para ampliar as reservas brasileiras, que hoje é o esteio, praticamente, de toda política econômica. Ao mesmo tempo há de se considerar o impacto local dessas remessas nas comunidades de origem dos migrantes, via os investimentos produtivos e sustento de famílias. Esse quadro nos mostra que não há uma visão clara com relação a integração do imigrante com propostas de políticas públicas. Facilitar o acesso à documentação é primordial - documento de residência, CPF, carteira de 
trabalho - mas não o bastante se buscamos a integração do imigrante na sociedade brasileira.

\section{P. Que cenário é possível traçar para os fluxos migratórios mundiais em um momento de ascensão e consolidação de movimentos, partidos e governos ultra-conservadores?}

R: O que acontece hoje, na realidade, não é nada mais nada menos que uma reação a uma situação de crise econômica. Quando o capital perde sua forma de acumulação ele precisa fazer reformas, e nesse processo de reformas é necessário trazer movimentos que têm visões conservadoras, que envolvem até sociedades teocráticas. Ou seja, seria a vontade de Deus que tal situação aconteça, e a partir daí você pode buscar refúgio em um local onde haverá alguém que irá dizer que a situação pela qual você passa está prevista nos planos de Deus e que você deve se resignar ou procurar na fé fazer tais mudanças. Isso é um processo de realinhamento de toda questão econômica e política mundial. Esses governos populistas atendem a esses chamados. No entanto, há uma situação que é muito clara, principalmente nos países em desenvolvimento, o processo de transição demográfica nesses países já está chegando ao final, isto é, as altas taxas de mortalidade e natalidade observadas no passado, e que levavam a um pífio crescimento da população, tiveram quedas em período muito curto de tempo, 25 ou 30 anos, comparados com o padrão médio de 150 anos para a transição na Europa. Esse processo, em um primeiro momento, gerou altas taxas de crescimento populacional e, em período recente, ao se completar a transição, indica taxas de crescimento muito reduzidas e, em futuro próximo, aponta para taxas negativas. Com isso chegamos a um momento em que a população está envelhecendo, não só por conta de sobrevida dos idosos, mas, principalmente, pela queda da fecundidade. Isto é, a estrutura etária de uma população envelhecida onde há uma redução da população economicamente ativa e da força de trabalho. Portanto, os países que completaram a transição têm necessidade de atrair população em idade laboral. $\mathrm{O}$ que hoje está sendo colocado não é uma postura contra a migração, mas contra uma migração que não pode ser controlada. A visão da migração altamente qualificada, a visão da migração de pessoas com conhecimento técnico que possa 
entrar rapidamente no mercado de trabalho é aceita por todos os países, aliás, mais do que aceita, é incentivada. Então, nesse quadro a proposta dos países é de fechar as fronteiras, mas deixar uma porta pela qual, seletivamente, as pessoas possam entrar. É desejável que o imigrante regular preste seus serviços e no momento da aposentadoria volte ao seu país de origem, e não acarrete novos custos ao sistema previdenciário do país de acolhida. Nesse contexto de exploração, alguns trabalhos mostram que apesar do grande volume de remessas que o México recebe dos Estados Unidos, isto é dos imigrantes mexicanos que estão naquele país, o aporte que o México faz para os americanos em termos de transferência de investimentos sociais, é três ou quatro vezes maior que os ganhos com as remessas. Isso significa que a pessoa ao ir para os Estados Unidos que já tem, por exemplo, alguma formação escolar, o custo dessa formação foi bancado pela sociedade mexicana, e quem vai melhor aproveitar esse investimento é a sociedade dos Estados Unidos. Sendo que o pagamento desse custo para a sociedade mexicana será por meio de remessas, que não compensa, em termos monetários, aqueles recursos que foram aplicados. Assim, a estratégia seguida é buscar o especialista formado dentro em uma escola no país de origem. Muitas vezes a escola que seguem dogmas das escolas do país de destino, escolas de formação médica que tem todo seu currículo voltado para um país do hemisfério norte, ou mesmo na economia, na engenharia, que preparam os futuros imigrantes. $O$ que se tem na atualidade é o incentivo a migração de determinado grupo, mas também a criação de outros caminhos, pequenas válvulas, que possam absorver a mão de obra menos qualificada, uma vez que ela também é demandada pelo mercado de trabalho. No entanto, esse grupo estará sempre em uma posição subalterna de mais baixa remuneração na pirâmide laboral, em situações de grande exploração. Ao mesmo tempo, em caso de qualquer problema, o imigrante pode ser devolvido ao seu país ou a qualquer local, pouco importando o tempo de residência ou se está trabalhando no país de destino. É importante sublinhar que alguns países europeus criaram programas para o retorno "voluntário" de imigrantes. Quando cessam as oportunidades de trabalho, por exemplo em caso de uma crise, o imigrante pode buscar o auxílio de instituições para apoiar o retorno ao país de origem. Esses programas têm custos para o imigrante, por exemplo, se ele é detentor de algum tipo de autorização de permanência ela é cassada e, por um período de tempo que varia de 3 a 5 anos, fica 


\section{ENTREVISTA - DUVAL MAGALHÃES FERNANDES}

impedido de retornar. Esses migrantes fazem parte de um conjunto de mão de obra que é utilizada e descartada. Nesse aspecto, os fluxos mundiais vão seguindo essa lógica, abrindo oportunidades quando há interesses, fechando as fronteiras quando essas desaparecem, e selecionando os melhores, os mais rentáveis para o trabalho. Em outras palavras, o sistema nos últimos anos foi aperfeiçoado de forma a criar mecanismos para selecionar a mão de obra, chegando mesmo em caso no qual o país interessado desloca pessoas para o país de origem do imigrante e ali faz a seleção tendo em conta as habilidades requeridas no destino. Essa lógica pode ser ampliada por programas de recrutamento permanente, como faz o Canadá, ou por programas de pontos, nos quais o imigrante tem de preencher alguns requisitos mínimos e estar disposto a residir no local que será indicado pelas autoridades migratórias, usualmente regiões de baixa densidade populacional. Após esses processos que podem levar anos, o tão sonhado visto ou carimbo no passaporte abre, no imaginário de quem migra, as portas do paraíso. No contato com a realidade local, em muitos casos, o sonho vira pesadelo, porque será sempre um cidadão de segunda categoria, e tendo sob a cabeça a espada da devolução ou da expulsão para o outro país. Em resumo, não há no horizonte perspectiva favorável para o imigrante, e dadas as condições políticas e econômicas nos países do hemisfério sul, países em desenvolvimento de uma maneira em geral, o sonho da emigração está sempre latente e do outro lado, no mítico destino, a lógica de construção de muros em lugar de pontes ganha cada dia mais adeptos. 